\title{
How COVID Affected our Python Class at the Worcester Public Library
}

\section{Melody Friedenthal}

In June 2020, ITAL published my account of how the Worcester Public Library (MA) came to offer a class in Python programming and how that class was organized. Although readers may have read the article in the middle of our COVID-year, I wrote it mostly in early January 2020, before libraries across the country closed in an effort to protect staff and patrons from the disease.

From spring 2020 through April 2021, I taught Intro to Coding: Python for Beginners five more times.

But, of course, these classes were not face-to-face. Like virtually all other library, musical, political, religious, and cultural programming across the world, our Python course-was taught virtually. The Public Services team has one professional Zoom account, which my colleagues and I share.

How did going remote affect this class? It depends on whether your perspective is that of a student or that of the instructor.

Many of us have read how difficult it's been for teachers to effectively reach their elementarythrough-collage-age students. I've had many of the same challenges, but since nearly all my students are adults and they all chose to take this class, I don't need to grapple with fidgety kids or recess. On the other hand, there were few distractions in our Computer Lab, while COVID-time students have to grapple with pets, children squabbling, or noise from a TV.

I was teaching from my home office. At the library I have one monitor but at home I have two, which makes it easier for me to spread out my assorted documents. To "protect" my students from seeing my messy house, I used a virtual background, one chosen not to distract. However, the software which determines the borders of a human presenter isn't perfect and there is sometimes a halo behind my head of the things behind me; this may be distracting itself.

Prior to COVID, since we had twelve seats in the Computer Lab, we limited registration to fourteen, allowing for some no-shows (and we have two spare laptops, in case everyone showed up). A week prior to session one I would email the registrants, asking them to confirm their continued interest. If a student didn't confirm, I'd give their seat to someone on the waitlist.

While I was not prepared to make my class a MOOC (Massive Open Online Courses) because I individually review homework and give lots of feedback, we did increase maximum registration to fifteen since the number of seats in the Computer Lab was no longer a limiting factor. And, as before, I ask for confirmation via email, but I also include in that email two links and an attached Word doc.

The document is an excerpt from Cory Doctorow's novel Little Brother on the joys of coding.

Melody Friedenthal (mfriedenthal@mywpl.org) is a Public Services Librarian, Worcester Public Library. (C) 2021. 
The first embedded link leads to the free version of Zoom. The second link is to the Thonny website (https://thonny.org). Thonny is a free IDE (Integrated Development Environment) where students can write and execute Python code. We used Thonny when I taught face-to-face, but the Lab computers all had Thonny installed, and were ready for students to use. Now, I have to depend on the ability of students to download the software to their own computers. I ask students to do the two downloads ahead of session one.

Which brings us to two problems: the class was no longer accessible to students who live in a household without a computer and internet service. And, as I found out with one prospective student, it's not accessible to patrons who don't have administrative rights to their computer; that is, the ability to download new software.

When a patron confirms their interest, I email them the course manual. It now contains about 93 pages. I told students they might choose to print it but doing so is up to individual preference. The advantage of having a digital copy is that students can search for keywords easily. The disadvantage is that the cost of printing the manual is shifted to the student and may be prohibitive for some.

In session one, I acknowledged that it's difficult to learn technical material via Zoom, and I encouraged everyone to ask questions during class and to email me if they are stymied while working on the homework. I reiterated that invitation during every session.

While teaching, I bounce back-and-forth between screen-sharing my Thonny window and the manual, while trying to keep an eye on the little Zoom windows showing my students. Some students cannot or choose not to turn on their video. This is a problem for me, since I can't readily determine who's asking a question. Moreover, it is helpful to associate a face with a name. And since I give out a Certificate of Completion to each student who does the homework and attends all sessions, I want to make sure the student is actually taking part. I've had students who sign in, leave their camera off, and then apparently leave (I call on students by name and sometimes the no-video ones never respond).

Offering the class online has advantages in snowy Worcester. Students can tune in from the comfort of their own homes, avoid the slick roads, bypassing paying for parking at the municipal lot next to our building or for a bus to downtown, or the discomfort of walking in a dark citycenter in the evening.

Another plus: as program organizers and program participants have discovered, with videoconferencing we are no longer limited geographically. I had registrants who live in Pennsylvania and Georgia.

As always, students range from total beginners to experienced programmers-of-other-languages. I've thought about how I can give extra time to the former while not boring the latter. One thing I've done is to make some assignments optional and say, "If you want an extra challenge, give this a try...."

I've slowed the class down a bit, leaving more time for coding during each session. If a student has difficulties, I invited them to share their screen. This pedagogical technique actually works better 
via Zoom than in-person, because we could all see that screen equally well. In the Computer Lab, only the student who sat at the same (2-person) desk could easily see what the other person had coded.

Another thing I've done is to ratchet down the formality of the class: I am chattier and demo fun games I've written, e.g., Hangman, Tic-Tac-Toe, Rock-Paper-Scissors, and You Sunk My Battleship, for inspiration.

I experimented with using the built-in Zoom whiteboard but that wasn't satisfactory, so I wrote supplementary notes as comments in Thonny.

Parents were fearful their kids were not being intellectually challenged when schools were closed due to the pandemic, so maybe I shouldn't have been surprised that the April 2021 class contained seven children. There would have been an eighth, but when I realized one registrant was just seven years old, I told his mother that, while she was the best judge of her son's abilities, I discouraged him from taking the class. She decided to take it herself.

\section{What patrons like most about our Digital Learning programs:}

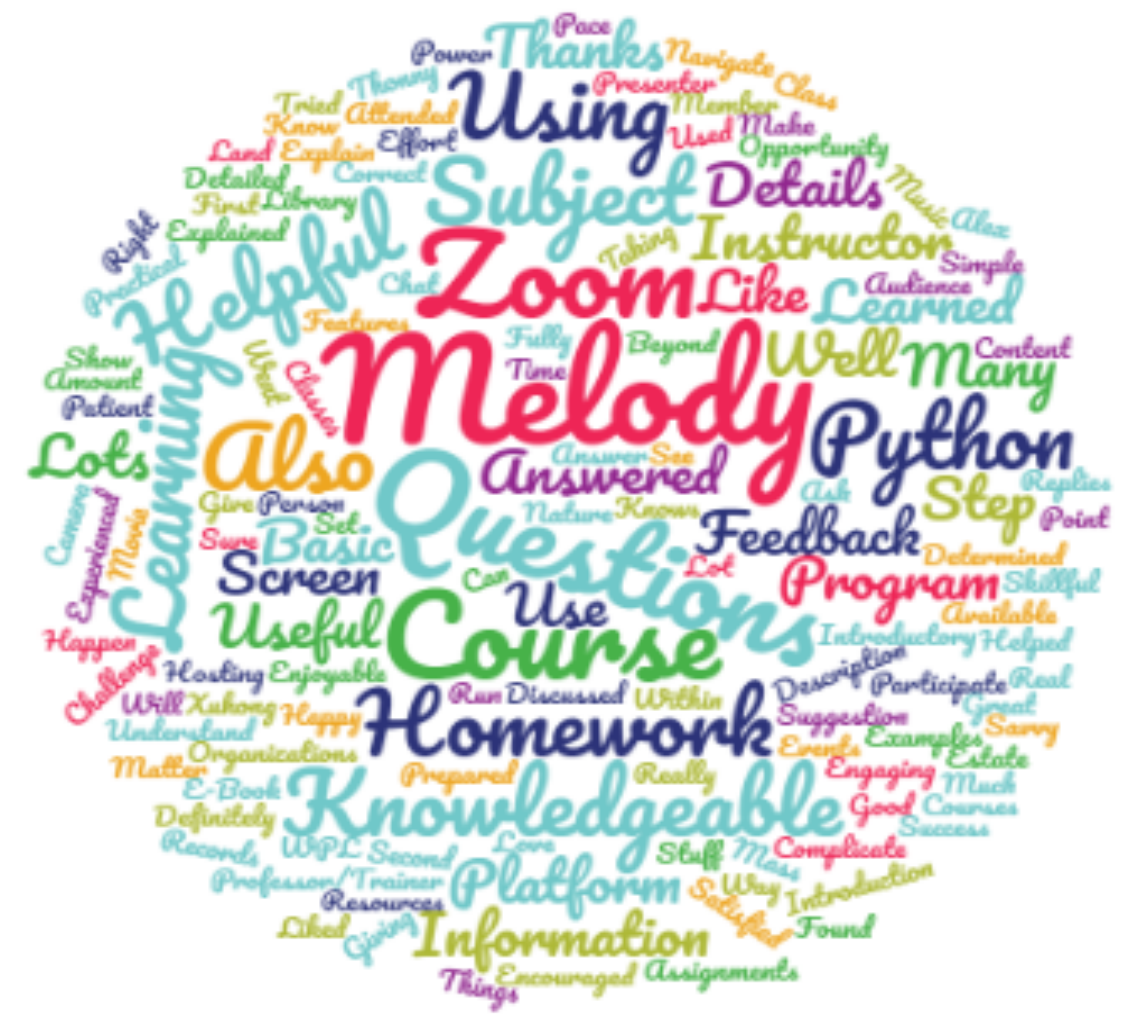

Figure 1. A word-cloud of our Fall 2020 Project Outcome evaluations (includes other Digital Learning programs).

At our sixth and final session I traditionally execute a program which draws colorful graphics, rather like Spirograph. Students were able to see each curve being drawn in a new window launched by the IDE. But this window doesn't exist until I executed the program. While we were 
using Zoom, when I attempted to share my screen, the students missed the first graphics, no matter how fast I was at screen-sharing. I made the execution "sleep" for a few seconds to give me time to switch screens before the graphics were drawn.

A larger percentage of students earned the Certificate of Completion during the virtual classes than on average in the in-person pre-covid classes, perhaps 75\% vs. 40\%. For the in-person classes our Communications Officer printed the Certificates on heavy paper adorned with the WPL logo; I signed each and handed them out during the final session. For our virtual classes, the certificates were digitally signed and then emailed; students could print them if they chose.

This follow-up is being written during October 2021, and with a substantial percentage of Massachusetts residents vaccinated for COVID, the Worcester Public Library is now back to offering many programs in-person, including Python. The City of Worcester requires mask use in all municipal buildings, and while some patrons don't cooperate, I've told my students that anyone not wearing a mask properly will be asked to leave the Computer Lab. With so many people out of work due to the economic devastation wrought by COVID, we were gratified to be able to offer a class that teaches in-demand skills, especially ones that can be applied in a work-from-home environment. 